\title{
BMJ Open Adaptation and validation of the Distress Scale for Mexican patients with type 2 diabetes and hypertension: a cross-sectional survey
}

Ingrid Patricia Martinez-Vega, ${ }^{1}$ Svetlana V Doubova, ${ }^{1}$ Rebeca Aguirre-Hernandez, ${ }^{2}$ Claudia Infante-Castañeda ${ }^{3}$

To cite: Martinez-Vega IP, Doubova SV, AguirreHernandez R, et al. Adaptation and validation of the Distress Scale for Mexican patients with type 2 diabetes and hypertension: a cross-sectional survey. BMJ Open 2016;6:e009723. doi:10.1136/bmjopen-2015009723

- Prepublication history and additional material is available. To view please visit the journal (http://dx.doi.org/ 10.1136/bmjopen-2015009723).

Received 14 August 2015 Revised 27 November 2015 Accepted 6 January 2016

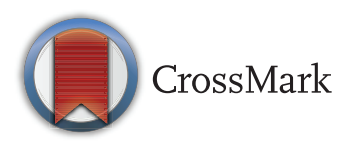

${ }^{1}$ Epidemiology and Health Services Research Unit, CMN Siglo XXI, Mexican Institute of Social Security, Mexico City, Mexico ${ }^{2}$ Departamento de Farmacología de la Facultad de Medicina, Universidad Nacional Autónoma de México, México City, Mexico ${ }^{3}$ Instituto de Investigaciones Sociales, Universidad Nacional Autónoma de México, México City, Mexico

Correspondence to Dr Svetlana V Doubova; svetlana.doubova@gmail.com

\section{ABSTRACT}

Objectives: The aim of this study was to adapt and validate the Distress Scale for Mexican patients with type 2 diabetes and hypertension (DSDH17M).

Setting: Two family medicine clinics affiliated with the Mexican Institute of Social Security.

Participants: 722 patients with type 2 diabetes and/or hypertension (235 patients with diabetes, 233 patients with hypertension and 254 patients with both diseases).

Design: A cross-sectional survey.

Methods: The validation procedures included: (1) content validity using a group of experts, (2) construct validity from exploratory factor analysis, (3) internal consistency using Cronbach's $\alpha$, (4) convergent validity between DSDH17M and anxiety and depression using the Spearman correlation coefficient, (5) discriminative validity through the Wilcoxon rank-sum test and (6) test-retest reliability using intraclass correlation coefficient.

Results: The DSDH17M has 17 items and three factors explaining $67 \%$ of the total variance. Cronbach $\alpha$ ranged from 0.83 to 0.91 among factors. The first factor of 'Regime-related Distress and Emotional Burden' moderately correlated with anxiety and depression scores. Discriminative validity revealed that patients with obesity, those with stressful events and those who did not adhere to pharmacological treatment had significantly higher distress scores in all DSDH17M domains. Test-retest intraclass correlation coefficient for DSDH17M ranged from 0.92 to 0.97 among factors.

Conclusions: DSDH17M is a valid and reliable tool to identify distress of patients with type 2 diabetes and hypertension.

\section{INTRODUCTION}

Distress is a non-psychiatric emotional burden in patients with chronic diseases. ${ }^{12}$ Emotional distress is non-specific to a chronic disease as observed in patients with diabetes, hypertension, cancer, multiple

\section{Strengths and limitations of this study}

- We adapted and validated the Diabetes Distress Scale (DDS17) for patients with type 2 diabetes and hypertension, considering that both are frequent chronic diseases often occurring together that have common risk factors, severe long-term complications and require several common selfcare strategies-circumstances that can cause distress.

- The study provides the evidence that the Distress Scale for Mexican patients with type 2 diabetes and hypertension (DSDH17M) is valid and reliable and describes specific problems that contribute to distress patients in these populations.

- The primary limitation of this study is that the DSDH17M validation was performed only in a group of patients treated at two family medicine clinics of Instituto Mexicano del Seguro Social (IMSS) in Mexico City, possibly limiting generalisability of the results.

sclerosis and HIV, among others. ${ }^{2}$ Its prevalence among patients with chronic disease varies according to disease type, severity, treatment, availability of psychological support by healthcare providers, family and community. ${ }^{2-6}$ Emotional distress may occur in response to the disease manifestation, progression, complications, impact on selfconcept and need of continuous nonpharmacological and pharmacological treatment, among others. ${ }^{2-5}$ Timely detection and management of emotional distress in patients with chronic disease is associated with better self-care, quality of life and health outcomes. ${ }^{7}$ Emotional distress needs to be differentiated from depression due to the differences in underlying treatment.

Diabetes and hypertension are two of the most common chronic diseases worldwide. Furthermore, the prevalence of hypertension in persons with diabetes varies between $50 \%$ 
and $90 \% .{ }^{8}$ Up to $75 \%$ of patients with diabetes die from cardiovascular disease attributed to hypertension. ${ }^{9}$ Yet, most research on emotional distress focuses primarily on diabetes with little concern regarding to hypertension or their co-occurrence. Several Diabetes Distress Scales (DDS) have been validated, whereas according to our knowledge the General Health Questionnaire (12GHQ) is the only scale that has been used for measuring hypertension-related distress. ${ }^{5}$ Furthermore, 12GHQ and several specific distress scales (eg, Problem Areas in Diabetes (PAID) scale) lack some dimensions of the construct (eg, patients' feelings about their healthcare provider) that are relevant for patients with chronic diseases. ${ }^{10}$ To overcome these problems, the DDS17 was developed with the aim of measuring patients distress levels in response to the emotional burden, care regimen, interpersonal factors and physician care. ${ }^{10}$ However, this scale focuses only on patients with diabetes.

Type 2 diabetes and hypertension are frequently coexistent chronic diseases with common socially determined lifestyle risk factors (eg, stress, sedentary lifestyle, unhealthy food). When poorly controlled, both diseases can cause severe long-term complications. Their control requires adherence to common self-care strategies (eg, diet, physical exercise and pharmacological treatment) and continuous monitoring (eg, visits to the healthcare professionals, laboratory tests, self-monitoring of blood pressure and blood sugar). All the factors mentioned above can provoke distress. The recognition of these common circumstances of chronic diseases has led healthcare researchers to the development of an Integrated Chronic Care Model that focus on integrative healthcare of chronic patients. ${ }^{11}$ Also, the magnitude of chronic diseases has prompted to build a measurement framework for the burden of treatment in patients with chronic conditions. ${ }^{12}$ All these efforts acknowledge that today patients have frequent multiple chronic comorbidity that requires general tasks of treatment and self-care.

In Mexico, the prevalence of type 2 diabetes and hypertension in adults is high. The prevalence of diabetes increased from $7 \%$ in 2006 to $9.2 \%$ in 2012 , whereas the prevalence of hypertension has remained at $31.5 \%{ }^{13}$ Mexican studies on emotional disorders among diabetic and hypertensive patients focus primarily on depression and have reported a high prevalence $(24-48 \%) .{ }^{14-16}$ Although it is recognised that emotional distress is frequent in patients with diabetes and hypertension, little is known about the magnitude of this problem in Mexico; hence, its study and clinical treatment are likely to be deficient. One of the reasons for the paucity of research on emotional distress in patients with diabetes and hypertension in Mexico is the lack of a rigorously validated instrument for assessment of this condition. To our knowledge, an attempt was made to validate the PAID scale. ${ }^{17} 18$ However, this Mexican adoption of PAID only has partial validation that includes construct validity through exploratory factor analysis, internal consistency with Cronbach's $\alpha$ and convergent validity analysis and lacks the content validity; furthermore, it has the same deficiencies regarding the dimensions of the PAID construct as the original scale. ${ }^{1718}$

To close these gaps in the literature, the objective of this study was to adapt and validate a Mexican version of the distress scale for patients with type 2 diabetes and hypertension.

\section{METHODS}

In 2014, we conducted a cross-sectional survey in two family medicine clinics affiliated with the Mexican Institute of Social Security (IMSS). The IMSS extends coverage to $48.8 \%$ of the Mexican population, providing healthcare for employees in the formal labour sector and their families. ${ }^{19}$ Clinics were selected according to convenience from the list of IMSS Mexico City ambulatory clinics: one from the northern area and the other from the southern area of the city. The clinics had the same services and infrastructure.

\section{Participants}

The inclusion criteria considered patients 20 years of age or older, with type 2 diabetes, hypertension or both and with at least 3 months since their diagnosis. We focused on patients with type 2 diabetes, as at IMSS patients with type 1 diabetes usually attend follow-up visits with specialist at the secondary care hospital settings, while patients with type 2 diabetes (that accounts for more than $90 \%$ of all diagnosed diabetes cases at IMSS) receive care from family doctors at the family medicine clinics.

Two nurses received a 1-week training course to supervise the fieldwork including participant identification and recruitment and questionnaire application. Nurses interviewed all available patients with type 2 diabetes and/or hypertension in the morning and evening shifts. Patients fulfilled the inclusion criteria and agreed to participate in the study after signing informed consent. Nurses also verified the patients' height, weight, diagnoses and treatment in the electronic health records.

\section{Study variables}

The primary study variable was emotional distress. We adopted the $\operatorname{DDS}^{10} 7^{10}$ for patients with diabetes and hypertension and validated it in the sample of Mexican patients. The original DDS is a 17 -item scale with four domains: distress associated with emotional burden, care regimen, interpersonal factors and physician care. ${ }^{10}$ Each item is rated on a 6-point scale ranging from 'not a problem' to 'a very serious problem'. The mean score was obtained for each domain as the sum of the items in each domain divided by the number of items in the domain.

To describe the characteristics of the study population and validate the distress scale for patients with diabetes and hypertension (DSDH17M), we collected information 
regarding patient's age; sex; education and marital, employment and nutritional status. Nutritional status was classified into four groups according to body mass index (BMI): low weight $\left(\mathrm{BMI}<18.5 \mathrm{~kg} / \mathrm{m}^{2}\right)$, normal weight (BMI 18.5$24.9 \mathrm{~kg} / \mathrm{m}^{2}$ ), overweight (BMI $25.0-29.9 \mathrm{~kg} / \mathrm{m}^{2}$ ) and obese $\left(B M I \geq 30.0 \mathrm{~kg} / \mathrm{m}^{2}\right)$. A stressful event was considered if the response was affirmative to the question of whether he/she had at least one negative stressful event during the previous month. To facilitate the answer to this question we provided a list of 28 stressful events selected from the scale of Holmes and Rahe. ${ }^{20}$ Also, at the end of this list, the patient was asked if he/she had any other negative stressful event during the previous month.

We included information on the clinical history such as duration of diabetes and/or hypertension after diagnosis and presence of any diabetes and/or hypertensionrelated complications. The Hospital Anxiety and Depression Scale (HADS) assessed depression (seven items) and anxiety (seven items) ${ }^{21}$ using a 4-point Likert response format with each subscale ranging from 0 to 21 . Scores $\geq 11$ identify the possible presence of anxiety or depression. Adherence to pharmacological treatment was ascertained when a patient reported complying with the indicated doses and schedules for all prescribed medications during the prior month. Blood pressure control was defined when, during the medical visit, blood pressure was $<130 / 80 \mathrm{~mm} \mathrm{Hg}$ for patients with comorbidity of diabetes and hypertension and $<140 / 90 \mathrm{~mm} \mathrm{Hg}$ for those who only had hypertension. ${ }^{22}$ Glucose control was defined when the patient had glycated haemoglobin (HbA1C) $<7$ or in the absence of this test when their fasting plasma glucose was $<130 \mathrm{mg} / \mathrm{dL}$ in the last measurement. ${ }^{23}$

\section{Procedures}

The sample size was based on the practice of ensuring a person-to-item ratio of 10:1. ${ }^{24}$ It also considered $20 \%$ of losses during the survey $(<80 \%$ of the information obtained). Therefore, minimum sample size calculated was 221 patients for each diagnosis (diabetes, hypertension or both). Patients from two clinics were included to obtain the necessary sample size and greater generalisability of the study results.

Validation of the DSDH17M was performed in two stages as follows:

Stage 1: DDS17 was translated into (Mexican) Spanish by a bilingual translator and then translated back to English (back translation) by another bilingual translator. Adoption of the scale for both populations (patients with diabetes and/or hypertension) was achieved by including the phrase 'diabetes and/or hypertension' in each item. Then, a group of experts evaluated the content validity of the scale for both diseases. This group included two health systems researchers specialised in family medicine, one psychologist, one medical sociologist and one nurse. All members of the group had experience in the care of patients with diabetes and hypertension and validation of health assessment tools.
All members were invited to assess the appropriateness of the language and whether each item of the adapted DSDH17M was representative of the concept that the instrument purports to measure. Finally, experts rated each item as 1='not relevant', 2='useful but not relevant' or 3='relevant'. Expert responses were grouped and those who rated the items as 'relevant' were counted. Content validity index (CVI) for each item was calculated as $(n e-N / 2) /(\mathrm{N} / 2)$, where 'ne' was the number of experts who indicated the item as 'relevant' and ' $\mathrm{N}$ ' was the total number of experts. ${ }^{25}$ Content analysis showed that all DDS17 items can be applied for both diseases since all the items are formulated in general terms and avoid treatment and self-care particularities. There were no indications that items needed to be replaced or eliminated as all items obtained a CVI $>0.7$. Also, a pilot pretest of the scale in 25 patients was performed to assure clarity of items from a linguistic and cultural view. Online supplementary appendix 1 presents the adopted DSDH17M questionnaire.

Stage 2: Descriptive analysis served to depict participant's characteristics, calculate mean, SD, skewness, kurtosis and frequency of distribution of each item of the adopted DSDH17M questionnaire. Corrected item-total correlations were computed to determine if the behaviour of each item was consistent with the other items in the same factor of the original scale. ${ }^{26}$ Exploratory factor analysis was carried out based on the polychoric correlation matrix of the whole sample. Three and four factors were extracted using generalised least squares. In all cases, the solution was analysed without being rotated and after varimax, and oblimin rotations were applied. ${ }^{27}$ Factor loadings $>0.4$ were considered significant. ${ }^{28}$ Percentage of variance explained by each factor and communality of each item were computed.

We also performed separate factor analysis for patients with diabetes and hypertension and for those patients with both diseases, and carried out a multiple group confirmatory factor analysis ${ }^{29}$ to test whether the three groups of patients differed with regard to the underlying constructs. When successive invariance models (configural, weak, strong and strict) were compared, the incremental comparative fit index was $<0.01$, that is, the measurement model is invariant across the studied populations. Therefore, we present only the analyses for the whole sample of patients.

Cronbach's a and the average interitem correlation were used to measure the internal consistency of items associated with the same factor; a coefficients around 0.80 were considered acceptable. ${ }^{26}$ A score for each factor was calculated by summing all item responses within each factor and dividing by the total number of factor items. Convergent validity between the score factors and other measures of psychosocial well-beinganxiety and depression-were assessed by calculating Spearman's rank correlation coefficient; $r<0.35$ was considered to represent weak correlations, $r$ ranging from 0.36 to 0.67 represent moderate correlations and from 
0.68 to 1.0 high correlations. ${ }^{30}$ Wilcoxon rank-sum test served to evaluate the ability of the score factors to discriminate between subpopulations defined by different clinical and personal characteristics of the participants. We hypothesised that females with less education, those who reported stressful events and emotional problems, had obesity and complications of diabetes and/or hypertension, disease duration $<3$ years, did not adhere to treatment and did not have blood pressure and glucose control may present higher distress in all domains. ${ }^{4-6} 31$

Test-retest reliability was assessed by applying the DSDH17M twice with a lag time of 5 days to a subgroup of 35 participants. For each participant, two global mean scores and two mean scores for each factor were calculated and compared using the intraclass correlation coefficient (ICC); ICG $>0.75$ was considered excellent, $0.40-0.75$ fair to good and $<0.40$ poor. $^{32}$ All analyses were performed with R Core Team 2015 V.3.1.3 and STATAV.12.

\section{RESULTS}

Of 856 eligible patients, $722(84.3 \%)$ agreed to participate. Reasons for not accepting to participate were the lack of time $(61.9 \%)$, no interest in responding to the survey $(27.6 \%)$ and fatigue or feeling poorly $(10.5 \%)$.

Table 1 describes the general characteristics, nutritional status, medical history, adherence to pharmacological treatment and disease control of study participants. The study included 722 patients, the majority being female $(73 \%)$. Mean age was $58.2 \pm 10.4$ years. Almost half $(47 \%)$ completed only elementary school or less and were not employed. Most participants lived with a life partner. A total of $0.3 \%$ had a low weight, $16.0 \%$ had a normal weight, 36.1 were overweight and $47.6 \%$ had obesity; $32.5 \%$ had diabetes, $32.3 \%$ had hypertension and $35.2 \%$ had both diseases. Median time elapsed since diagnosis was 8 years; $61.5 \%$ had diabetes and/or hypertension complications, $12.3 \%$ reported some stressful event in the last month, 22\% had anxiety and 9\% had depression according to the HAD scale, whereas $54.8 \%$ attained good treatment adherence, $54.4 \%$ had blood pressure control and $46 \%$ of patients with diabetes had glucose control. Furthermore, online supplementary appendix 2 describes patients' characteristics according to the disease group (diabetes, hypertension and both diseases).

Table 2 presents summary statistics of the DSDH17M. 'Not a problem' was the most frequent response for all items of the questionnaire. The three items in which most participants responded not having a problem were feeling that 'the physician does not have sufficient knowledge about diabetes and/or hypertension', 'friends or family do not provide emotional support' and 'friends or family do not appreciate how difficult living with diabetes and/or hypertension can be'. The three items with the highest percentages of responses of having somewhat serious, serious or very serious problems were feeling that 'he/she will end up with serious
Table 1 General characteristics, nutritional status, medical history, adherence to treatment and disease control $(n=722)$

\begin{tabular}{|c|c|}
\hline & Per cent \\
\hline \multicolumn{2}{|l|}{ General characteristics } \\
\hline \multicolumn{2}{|l|}{ Sex } \\
\hline Male & 27.0 \\
\hline Female & 73.0 \\
\hline Age, years, mean (SD) & $58.18(10.4)$ \\
\hline \multicolumn{2}{|l|}{ Age groups } \\
\hline$<65$ & 71.2 \\
\hline$\geq 65$ & 28.8 \\
\hline \multicolumn{2}{|l|}{ Schooling } \\
\hline Elementary school or less & 47.0 \\
\hline Secondary school or higher & 53.0 \\
\hline \multicolumn{2}{|l|}{ Occupation } \\
\hline Retired or pensioner & 22.6 \\
\hline Remunerated job & 30.3 \\
\hline Not employed & 47.1 \\
\hline Married or with life partner & 64.4 \\
\hline \multicolumn{2}{|l|}{ Nutritional status } \\
\hline Low weight & 0.3 \\
\hline Normal weight & 16.0 \\
\hline Overweight & 36.1 \\
\hline Obese & 47.6 \\
\hline \multicolumn{2}{|l|}{ Medical history } \\
\hline Type 2 diabetes & 32.5 \\
\hline Hypertension & 32.3 \\
\hline Diabetes and hypertension & 35.2 \\
\hline $\begin{array}{l}\text { Duration of diabetes and/or hypertension, } \\
\text { years, mean (SD) }\end{array}$ & $8.7(6.2)$ \\
\hline $\begin{array}{l}\text { Complications of diabetes and/or } \\
\text { hypertension }\end{array}$ & 61.5 \\
\hline $\begin{array}{l}\text { Presence of stressful events in the last } \\
\text { month }\end{array}$ & 12.3 \\
\hline Anxiety & 22.0 \\
\hline Depression & 9.0 \\
\hline \multicolumn{2}{|l|}{ Number of medications } \\
\hline $1-2$ & 23.5 \\
\hline $3-4$ & 36.5 \\
\hline$\geq 5$ & 40.0 \\
\hline \multirow[t]{2}{*}{ Insulin therapy in patients with diabetes } & $n=489$ \\
\hline & 25.4 \\
\hline Adherence and disease control & $n=722$ \\
\hline Adherence to pharmacological treatment & 54.8 \\
\hline Blood pressure control & 54.4 \\
\hline \multirow[t]{2}{*}{ Glucose control } & $n=489$ \\
\hline & 46.0 \\
\hline
\end{tabular}

long-term complications regardless of what they do' $(28.7 \%)$, 'diabetes and/or hypertension are consuming too much of their mental and physical energy' (28.6\%) and 'he/she is not closely adhering to a good meal plan' $(28.3 \%)$.

Corrected item-total correlations were $>0.47$, therefore the response to any given item was consistent with those of other items in the same dimension as in the original DDS17. SDs were $>1$, thus an adequate variability among responses was observed. Nevertheless, means ranged from 1.5 to 3 so the distribution of the answers had a 
Table 2 Descriptive statistics and item-total correlations of DSDH17M $(n=722)$

\begin{tabular}{|c|c|c|c|c|c|c|c|c|c|c|}
\hline Items & $\begin{array}{l}\text { Not a } \\
\text { problem } \\
\text { Per cent }\end{array}$ & $\begin{array}{l}\text { Slight } \\
\text { problem } \\
\text { Per cent }\end{array}$ & $\begin{array}{l}\text { Moderate } \\
\text { problem } \\
\text { Per cent }\end{array}$ & $\begin{array}{l}\text { Somewhat } \\
\text { serious } \\
\text { problem } \\
\text { Per cent }\end{array}$ & $\begin{array}{l}\text { Serious } \\
\text { problem } \\
\text { Per cent }\end{array}$ & $\begin{array}{l}\text { Very } \\
\text { serious } \\
\text { problem } \\
\text { Per cent }\end{array}$ & M (SD) & Skewness & Kurtosis & $\begin{array}{l}\text { Corrected } \\
\text { item-total } \\
\text { correlation }\end{array}$ \\
\hline \multicolumn{11}{|l|}{ Emotional burden } \\
\hline $\begin{array}{l}\text { Feeling overwhelmed by the demands of living } \\
\text { with diabetes and/or hypertension }\end{array}$ & 40.7 & 17.6 & 19.3 & 7.2 & 11.1 & 4.2 & $2.43(1.54)$ & 0.79 & -0.55 & 0.77 \\
\hline $\begin{array}{l}\text { Feeling angry, scared and/or depressed when } \\
\text { I think about living with diabetes and/or } \\
\text { hypertension }\end{array}$ & 43.5 & 13.3 & 16.5 & 8.4 & 12.0 & 6.2 & $2.51(1.66)$ & 0.72 & -0.83 & 0.73 \\
\hline $\begin{array}{l}\text { Feeling that diabetes and/or hypertension } \\
\text { control my life }\end{array}$ & 52.9 & 11.5 & 13.0 & 6.9 & 10.4 & 5.3 & $2.26(1.63)$ & 0.98 & -0.42 & 0.68 \\
\hline $\begin{array}{l}\text { Feeling that diabetes and/or hypertension are } \\
\text { taking up too much of my mental and physical } \\
\text { energy everyday }\end{array}$ & 31.0 & 17.3 & 23.0 & 9.3 & 12.7 & 6.6 & $2.75(1.60)$ & 0.53 & -0.88 & 0.62 \\
\hline $\begin{array}{l}\text { Feeling that I will end up with serious long-term } \\
\text { complications, no matter what I do } \\
\text { Regimen-related distress }\end{array}$ & 31.7 & 18.8 & 20.8 & 7.9 & 13.9 & 6.9 & $2.74(1.63)$ & 0.56 & -0.92 & 0.61 \\
\hline $\begin{array}{l}\text { Not feeling confident in my day-to-day ability to } \\
\text { manage diabetes and/or hypertension }\end{array}$ & 64.4 & 11.2 & 10.2 & 4.6 & 7.1 & 2.5 & $1.86(1.40)$ & 1.52 & 1.13 & 0.73 \\
\hline $\begin{array}{l}\text { Not feeling motivated to keep up my diabetes } \\
\text { and/or hypertension self-management }\end{array}$ & 58.2 & 12.2 & 13.3 & 5.7 & 7.5 & 3.2 & $2.02(1.46)$ & 1.28 & 0.44 & 0.69 \\
\hline $\begin{array}{l}\text { Feeling that I am often failing with my diabetes } \\
\text { and/or hypertension routine }\end{array}$ & 45.2 & 22.6 & 16.2 & 5.4 & 7.9 & 2.8 & $2.17(1.40)$ & 1.12 & 0.28 & 0.69 \\
\hline $\begin{array}{l}\text { Feeling that I am not sticking closely enough to } \\
\text { a good meal plan }\end{array}$ & 35.5 & 17.9 & 18.4 & 9.4 & 13.6 & 5.3 & $2.64(1.61)$ & 0.59 & -0.91 & 0.60 \\
\hline $\begin{array}{l}\text { Feeling that I am not testing my blood sugars } \\
\text { and/or blood pressure frequently enough } \\
\text { Interpersonal distress }\end{array}$ & 60.5 & 10.7 & 12.5 & 4.8 & 8.0 & 3.5 & $2.00(1.48)$ & 1.32 & 0.49 & 0.54 \\
\hline $\begin{array}{l}\text { Feeling that friends or family do not appreciate } \\
\text { how difficult living with diabetes and/or } \\
\text { hypertension can be }\end{array}$ & 72.3 & 8.6 & 6.5 & 3.2 & 6.4 & 3.0 & $1.72(1.38)$ & 1.87 & 2.22 & 0.86 \\
\hline $\begin{array}{l}\text { Feeling that friends or family do not give me the } \\
\text { emotional support that I would like }\end{array}$ & 75.1 & 6.1 & 6.0 & 3.9 & 5.5 & 3.5 & $1.69(1.39)$ & 1.92 & 2.40 & 0.80 \\
\hline $\begin{array}{l}\text { Feeling that friends or family are not supportive } \\
\text { enough of self-care efforts (eg, planning } \\
\text { activities that conflict with my schedule, } \\
\text { encouraging me to eat the 'wrong' foods) } \\
\text { Physician-related distress }\end{array}$ & 71.6 & 8.9 & 7.6 & 2.8 & 6.2 & 2.9 & $1.72(1.36)$ & 1.87 & 2.28 & 0.78 \\
\hline \multirow[t]{2}{*}{$\begin{array}{l}\text { Feeling that my doctor does not take my } \\
\text { concerns seriously enough. }\end{array}$} & 59.1 & 7.2 & 8.6 & 5.0 & 10.2 & 9.8 & $2.30(1.81)$ & 1.01 & -0.59 & 0.77 \\
\hline & & & & & & & & & & Continued \\
\hline
\end{tabular}




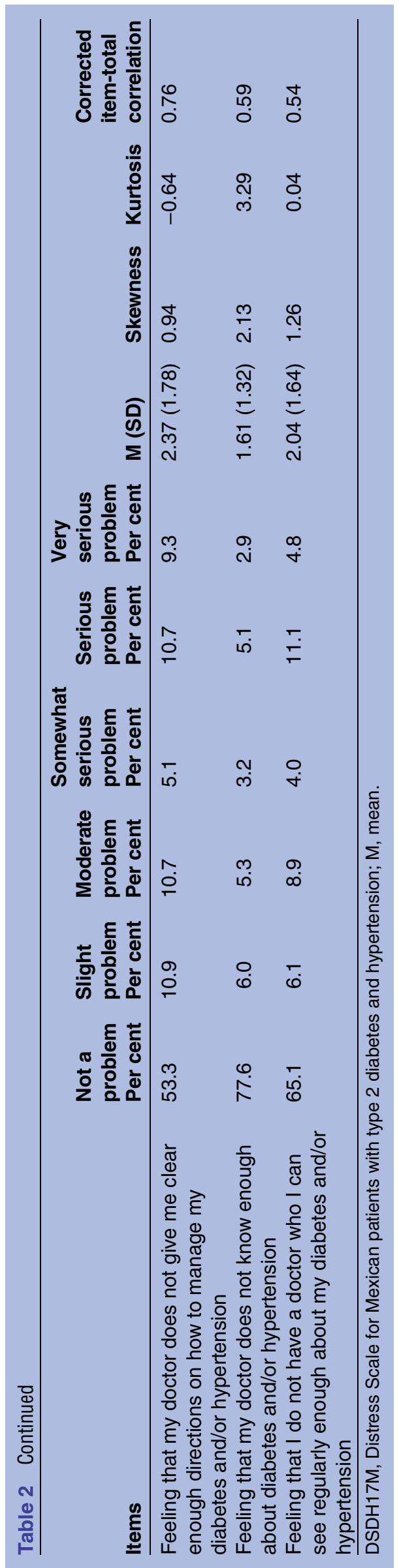

positive skew for every item. Most responses were in the lower end of the Likert response format; specifically, more than $70 \%$ of the patients chose one of the following responses: $1=$ not a problem, $2=$ a slight problem or $3=$ a moderate problem.

Online supplementary appendix 3 provides information on descriptive statistics and item-total correlations of DSDH17M according to the disease group (diabetes, hypertension and both diseases).

Table 3 presents the three-factor model with a varimax rotation. This model was similar to the three-factor model with an oblimin rotation. The four-factor models (with a varimax rotation and with an oblimin rotation) did not produce a loading matrix with a simple structure and a Heywood case was reported in one case. The model in table 3 explained $67 \%$ of the total variance. Ten items were associated with factor 1 labelled as 'regimen-related distress and emotional burden'. This factor explained $33 \%$ of variance. Items associated with factor 1 had communality values between 0.37 and 0.78 . Three items defined factor 2 referred to as 'interpersonal distress'. This factor explained $16 \%$ of the total variance and had communalities between 0.80 and 0.93 . Finally, four items were related to factor 3 called 'physicianrelated distress'. Factor 3 explained 18\% of the total variance and communalities ranged from 0.51 to 0.88 .

Table 4 presents the results of reliability and convergent validity analysis. The average interitem correlation was $>0.5$ for the three factors. Internal consistency as measured by Cronbach a was 0.91 for factors 1 and 2 with $95 \%$ CIs (95\% CI 0.89 to 0.93 ) and (95\% CI 0.85 to 0.96 ), respectively. Cronbach a for factor 3 was 0.83 (95\% CI 0.78 to 0.88 ). For the whole set of items, Cronbach a was 0.91 (95\% CI 0.89 to 0.92$)$ and the average interitem correlation was 0.37 .

The scores of the three domains of the DSDH17M had a positive and significant correlation with the anxiety and depression HADS subscales. Factor 1 of the DSDH17M was moderately correlated with anxiety $(\mathrm{r}=0.533, \mathrm{p}<0.0001)$ and depression subscales $(\mathrm{r}=0.525$, $\mathrm{p}<0.0001)$ of HADS, whereas the other two factors had a weak correlation with anxiety and depression subscales.

Discriminative validity analysis is summarised in table 5 . Wilcoxon rank-sum test indicated that women, patients with obesity and those with stressful events and nonadherence to pharmacological treatment had significantly higher distress scores in all DSDH17M domains.

The test-retest ICCs were 0.92 for physician-related distress, 0.96 for regimen-related distress and emotional burden, 0.97 for interpersonal distress, and for the average of all items.

\section{DISCUSSION}

This study has two important contributions to the analysis of patients with chronic distress. It adapts DDS17 for patients with diabetes and/or hypertension and provides the evidence that the Distress Scale for Mexican 
Table 3 Factor analysis of DSDH17M $(n=722)$

\begin{tabular}{|c|c|c|c|c|}
\hline \multirow[b]{2}{*}{ Items } & \multicolumn{3}{|l|}{ Factor loadings } & \multirow[b]{2}{*}{$\begin{array}{l}\text { Communality } \\
\text { values }\end{array}$} \\
\hline & $\begin{array}{l}\text { F1 } \\
\text { Regimen-related } \\
\text { distress and } \\
\text { emotional burden }\end{array}$ & $\begin{array}{l}\text { F2 } \\
\text { Interpersonal } \\
\text { distress }\end{array}$ & $\begin{array}{l}\text { F3 } \\
\text { Physician-related } \\
\text { distress }\end{array}$ & \\
\hline $\begin{array}{l}\text { Feeling overwhelmed by the demands of living } \\
\text { with diabetes and/or hypertension }\end{array}$ & 0.85 & 0.09 & 0.12 & 0.75 \\
\hline $\begin{array}{l}\text { Not feeling confident in my day-to-day ability to } \\
\text { manage diabetes and/or hypertension }\end{array}$ & 0.84 & 0.23 & 0.17 & 0.78 \\
\hline $\begin{array}{l}\text { Feeling angry, scared and/or depressed when } \\
\text { I think about living with diabetes and/or } \\
\text { hypertension }\end{array}$ & 0.80 & 0.16 & 0.20 & 0.71 \\
\hline $\begin{array}{l}\text { Not feeling motivated to keep up my diabetes } \\
\text { and/or hypertension self-management }\end{array}$ & 0.81 & 0.20 & 0.19 & 0.74 \\
\hline $\begin{array}{l}\text { Feeling that diabetes and/or hypertension control } \\
\text { my life }\end{array}$ & 0.75 & 0.17 & 0.11 & 0.60 \\
\hline $\begin{array}{l}\text { Feeling that diabetes and/or hypertension are } \\
\text { taking up too much of my mental and physical } \\
\text { energy every day }\end{array}$ & 0.70 & 0.06 & 0.08 & 0.49 \\
\hline $\begin{array}{l}\text { Feeling that I am often failing with my diabetes } \\
\text { and/or hypertension routine }\end{array}$ & 0.72 & 0.26 & 0.17 & 0.61 \\
\hline $\begin{array}{l}\text { Feeling that I will end up with serious long-term } \\
\text { complications, no matter what I do }\end{array}$ & 0.68 & 0.20 & 0.09 & 0.51 \\
\hline $\begin{array}{l}\text { Feeling that I am not testing my blood sugars and } \\
\text { blood pressure frequently enough }\end{array}$ & 0.52 & 0.22 & 0.24 & 0.37 \\
\hline $\begin{array}{l}\text { Feeling that I am not sticking closely enough to a } \\
\text { good meal plan }\end{array}$ & 0.56 & 0.34 & 0.14 & 0.44 \\
\hline $\begin{array}{l}\text { Feeling that friends or family do not appreciate } \\
\text { how difficult living with diabetes and/or } \\
\text { hypertension can be }\end{array}$ & 0.27 & 0.88 & 0.28 & 0.93 \\
\hline $\begin{array}{l}\text { Feeling that friends or family are not supportive } \\
\text { enough of self-care efforts (eg, planning activities } \\
\text { that conflict with my schedule, encouraging me to } \\
\text { eat the 'wrong' foods) }\end{array}$ & 0.25 & 0.80 & 0.30 & 0.80 \\
\hline $\begin{array}{l}\text { Feeling that friends or family do not give me the } \\
\text { emotional support that I would like }\end{array}$ & 0.30 & 0.82 & 0.30 & 0.86 \\
\hline $\begin{array}{l}\text { Feeling that my doctor does not give me clear } \\
\text { enough directions on how to manage my diabetes } \\
\text { and/or hypertension }\end{array}$ & 0.06 & 0.20 & 0.91 & 0.88 \\
\hline $\begin{array}{l}\text { Feeling that my doctor does not take my concerns } \\
\text { seriously enough }\end{array}$ & 0.15 & 0.18 & 0.91 & 0.88 \\
\hline $\begin{array}{l}\text { Feeling that my doctor does not know enough } \\
\text { about diabetes and/or hypertension and also } \\
\text { about diabetes and/or hypertension care }\end{array}$ & 0.24 & 0.20 & 0.72 & 0.61 \\
\hline $\begin{array}{l}\text { Feeling that I do not have a doctor who I can see } \\
\text { regularly enough about my diabetes and/or } \\
\text { hypertension }\end{array}$ & 0.23 & 0.26 & 0.62 & 0.51 \\
\hline Per cent of the variance & 33 & 16 & 18 & $\begin{array}{l}\text { Total variance } \\
67\end{array}$ \\
\hline
\end{tabular}

Bold values highlight the factor loadings $>0.4$.

DSDH17M, Distress Scale for Mexican patients with type 2 diabetes and hypertension.

patients with type 2 diabetes and hypertension (DSDH17M) is valid and reliable.

Adaptation of psychological instruments is a complex process requiring evidence of the semantic equivalence of the items, cultural fit of the instrument and adequate psychometric properties. ${ }^{33}$ The original DDS17 is a well- known scale for measuring levels of diabetes distress and areas of concern that cause the distress. ${ }^{10}$ This scale was developed in English ${ }^{10}$ and later translated, adapted and validated in several cultures, including Danish, ${ }^{34}$ Norwegian, ${ }^{35}$ Chinese $^{36}$ and Chilean. ${ }^{37}$ The adaptation of a DDS17 for diabetes and hypertension is justified by 
Table 4 Reliability and convergent validity of DHDS17M ( $n=722)$

\begin{tabular}{|c|c|c|c|}
\hline & $\begin{array}{l}\text { F1 } \\
\text { Regimen-related distress } \\
\text { and emotional burden }\end{array}$ & $\begin{array}{l}\text { F2 } \\
\text { Interpersonal } \\
\text { distress }\end{array}$ & $\begin{array}{l}\text { F3 } \\
\text { Physician-related } \\
\text { distress }\end{array}$ \\
\hline Average interitem correlation & 0.51 & 0.77 & 0.55 \\
\hline Cronbach's $\alpha(95 \% \mathrm{Cl})$ & 0.91 (0.89 to 0.93$)$ & 0.91 (0.85 to 0.96$)$ & 0.83 (0.78 to 0.88$)$ \\
\hline \multicolumn{4}{|c|}{ Correlation among DSDH17M domains and HADS } \\
\hline Anxiety & $0.533^{\star}$ & $0.298^{*}$ & $0.268^{*}$ \\
\hline Depression & $0.525^{*}$ & $0.339^{*}$ & $0.225^{*}$ \\
\hline
\end{tabular}

Convergent validity between DSDH17M and anxiety and depression scales by calculating Spearman's rank correlation coefficient.

${ }^{*}$ Correlation is significant at the 0.0001 level.

DSDH17M, Distress Scale for Mexican patients with type 2 diabetes and hypertension; HADS, Hospital Anxiety and Depression Scale.

the frequent coexistence of both diseases, by the presence of general tasks of treatment and self-care that these diseases share and that can cause distress. Also, content validity of the DDS17 scale was achieved by the confirmation of the relevance of all the items of the DDS17 for both diseases by the group of experts.

During the content analysis of the DSDH17M, a concern was raised about the difficulties in interpreting

Table 5 Discriminative validity of DSDH17M through analysis of Wilcoxon rank-sum test $(n=722)$

\begin{tabular}{|c|c|c|c|c|}
\hline Variable & Categories & $\begin{array}{l}\text { F1 } \\
\text { Regimen-related } \\
\text { distress and } \\
\text { emotional burden }\end{array}$ & $\begin{array}{l}\text { F2 } \\
\text { Interpersonal } \\
\text { distress }\end{array}$ & $\begin{array}{l}\text { F3 } \\
\text { Physician-related } \\
\text { distress }\end{array}$ \\
\hline Mean (SD) & & $2.33(1.15)$ & $1.71(1.26)$ & 2.08 (1.34) \\
\hline \multirow[t]{2}{*}{ Median } & & 2.0 & 1.0 & 1.5 \\
\hline & & Median & Median & Median \\
\hline \multirow[t]{2}{*}{ Sex } & Female & 2.1 & 1.0 & 1.5 \\
\hline & Male & 1.8 & 1.0 & 1.3 \\
\hline \multirow[t]{2}{*}{ Schooling } & $\begin{array}{l}\text { Elementary school } \\
\text { or less }\end{array}$ & 2.0 & 1.0 & 1.5 \\
\hline & $\begin{array}{l}\text { Secondary school } \\
\text { or higher }\end{array}$ & 2.0 & 1.0 & 1.5 \\
\hline \multirow[t]{2}{*}{ Obesity } & Yes & 2.1 & 1.0 & 1.5 \\
\hline & No & 1.9 & 1.0 & 1.3 \\
\hline \multirow[t]{2}{*}{ Stressful events } & Yes & 3.0 & 1.7 & 2.5 \\
\hline & No & 1.9 & 1.0 & 1.3 \\
\hline \multirow[t]{2}{*}{ Duration of diabetes and/or hypertension } & $\leq 3$ year & 1.9 & 1.0 & 1.6 \\
\hline & $>3$ year & 2.0 & 1.0 & 1.5 \\
\hline \multirow[t]{2}{*}{ Complications of diabetes or hypertension } & Yes & 2.0 & 1.0 & 1.5 \\
\hline & No & 2.0 & 1.0 & 1.3 \\
\hline \multirow[t]{2}{*}{ Adherence to pharmacological treatment } & Yes & 1.8 & 1.0 & 1.3 \\
\hline & No & 2.4 & 1.0 & 1.8 \\
\hline \multirow[t]{2}{*}{ Blood pressure control } & Yes & 2.0 & 1.0 & 1.3 \\
\hline & No & 2.1 & 1.0 & 1.5 \\
\hline \multirow[t]{2}{*}{ Glucose control } & Yes & 1.9 & 1.0 & 1.3 \\
\hline & No & 2.1 & 1.0 & 1.5 \\
\hline \multicolumn{2}{|l|}{ Wilcoxon rank-sum } & p Value & p Value & p Value \\
\hline \multicolumn{2}{|l|}{ Sex } & 0.002 & 0.005 & 0.013 \\
\hline \multicolumn{2}{|l|}{ Schooling } & 0.840 & 0.489 & 0.596 \\
\hline \multicolumn{2}{|l|}{ Obesity } & 0.004 & 0.011 & 0.033 \\
\hline \multicolumn{2}{|l|}{ Stressful events } & $<0.0001$ & $<0.0001$ & $<0.0001$ \\
\hline \multicolumn{2}{|l|}{ Duration of diabetes and/or hypertension } & 0.299 & 0.652 & 0.321 \\
\hline \multicolumn{2}{|l|}{ Complications of diabetes or hypertension } & 0.913 & 0.494 & 0.170 \\
\hline \multicolumn{2}{|l|}{ Adherence to pharmacological treatment } & $<0.0001$ & 0.005 & 0.008 \\
\hline \multicolumn{2}{|l|}{ Blood pressure control } & 0.146 & 0.793 & 0.175 \\
\hline \multicolumn{2}{|l|}{ Glucose control } & 0.058 & 0.794 & 0.200 \\
\hline
\end{tabular}

DSDH17M, Distress Scale for Mexican patients with type 2 diabetes and hypertension. 
the results when both diseases co-occur. The conclusion was that in this case, the scale allows evaluating the level of distress and the area(s) of greater distress for both conditions and can be interpreted as the impact/ burden of comorbidity on the patient. Because one cannot be sure that some dimensions of the distress caused by one chronic disease do not overlap with dimensions of the distress that other chronic disease causes in the same patient, if measured with two scales that measure very similar domains of what causes the diseases distress. In fact, one could expect to find a joint effect that not even the patient can separate.

The DSDH17M adapted for Mexican patients with diabetes and/or hypertension has acceptable psychometric characteristics. Consistent with the original DDS17, the DSDH17M preserved 17 items. This is different from the results of the DDS validation in China ${ }^{36}$ and Chile ${ }^{37}$ where researchers eliminated several items (two and four, respectively). The factorial structure of DSDH17M has three factors. The first factor combined distress related to the treatment regimen and emotional burden, whereas the other two factors (interpersonal and physician-related distress) remained separate. This factor structure is different from the original scale that has four factors but is similar to the DDS validated in China (CDDS) ${ }^{36}$ The DSDH17M explained $67 \%$ of the total variance that was greater, comparing with the Chinese version $(62.4 \%)$.

Internal consistency of the DSDH17M was acceptable with Cronbach's $\alpha$ values ranging from 0.83 to 0.91 , similar to the original, Danish, Norwegian and Chinese scales and different from the results of the DDS validation in Chile, ${ }^{37}$ where Cronbach's a ranged from 0.62 to 0.75 . DSDH17M also has test-retest reliability higher than the Chinese version (0.97 vs 0.74$).{ }^{36}$ Regarding the convergent validity, the factor 'regimen-related distress and emotional burden' of DSDH17M was moderately correlated with anxiety and depression found during validation of Chinese and Norwegian versions of the DDS.

Discriminative validity analyses of the DSDH17M revealed higher distress for females, patients with obesity, those with stressful events and non-adherence to pharmacological treatment. Chinese researchers also found a correlation of DDS with obesity and quality of life. Contrary to results from other studies, DSDH17M score did not differ significantly according to the complications of diabetes $^{35}$ or hypertension, glucose ${ }^{134-37}$ or blood pressure control.

Multiple group confirmatory factor analysis indicated that the measurement model is invariant across studied populations. This finding is congruent with previous research identifying the presence of distress in patients with diabetes or hypertension. It also highlights the common problems related to distress in these patients. Congruent with the findings in Danish patients with type 1 diabetes, we found that for Mexican patients with diabetes 2 and/or hypertension the least frequent concerns were those related to physician-related distress. A high percentage of patients in both cultures reported that there was no problem regarding 'the physician does not have sufficient information about diabetes and/or hypertension'. The items in which most participants responded having serious problems were from the domain of regimen-related distress and emotional burdens: 'feeling that they will end up with serious long-term complications regardless of what they do' and that 'diabetes and/or hypertension are consuming too much of their mental and physical energy' were major concerns followed by 'feeling that they are not closely adhering to a good meal plan'. These problems were similar to those reported by the Danish study. These findings highlight the need for comprehensive team-based care as proposed by the Chronic Care Model where the physician, nurse, psychologist, nutritionist and other health providers work collaboratively to meet the needs of patients with chronic illnesses and build their practical skills and confidence in self-care and improve health outcomes. ${ }^{11} 38$

The primary limitation of this study is that the DSDH17M validation was performed only in a group of patients treated at two family medicine clinics of IMSS in Mexico City, possibly limiting generalisability of the results. Therefore, we recognise the need to validate DSDH17M in other settings in Mexico to corroborate the factor structure of this scale. Furthermore, the DSDH17M was validated only in a sample of patients with hypertension and type 2 diabetes; however, the original DDS17 was validated for patients with type 2 and type 1 diabetes. Thus, further validation of this scale in patients with type 1 diabetes in the Mexican context is advisable. Additionally, it would be worth to assess whether the instrument has sensitivity for detecting changes in distress over time.

In conclusion, DSDH17M is a valid and reliable tool to identify distress in patients with type 2 diabetes and/or hypertension and describe specific problems that contribute to patients with distress in these populations.

Acknowledgements The authors would like to thank medical directors of the IMSS Family Medicine Clinics Number 20 and 15. They are also grateful to nurse Leticia Rodriguez and Ana Jesica Maya García, their participation was invaluable to the successful completion of their field work.

Contributors IPM-V and SVD conceptualised the study and conducted the literature review. IPM-V, SVD and $\mathrm{CI}-\mathrm{C}$ participated in the process of content validity and in the field work. RA-H, IPM-V and SVD performed statistical analysis. IPM-V and SVD wrote the manuscript. $\mathrm{RA}-\mathrm{H}$ and $\mathrm{CI}-\mathrm{C}$ critically reviewed the manuscript for significant intellectual content. All authors approved the final manuscript.

Funding This research received no specific grant from any funding agency in the public, commercial or not-for-profit sectors.

Competing interests None declared.

Patient consent Obtained.

Ethics approval IMSS National Research and Ethics Committee approved the project. Authorisation number R-2013-785-034.

Provenance and peer review Not commissioned; externally peer reviewed. 
Data sharing statement This article has the supplementary files (see online supplementary appendixes 1-3). The dataset is available on request (svetlana. doubova@gmail.com).

Open Access This is an Open Access article distributed in accordance with the Creative Commons Attribution Non Commercial (CC BY-NC 4.0) license, which permits others to distribute, remix, adapt, build upon this work noncommercially, and license their derivative works on different terms, provided the original work is properly cited and the use is non-commercial. See: http:// creativecommons.org/licenses/by-nc/4.0/

\section{REFERENCES}

1. Fisher L, Hessler DM, Polonsky WH, et al. When is diabetes distress clinically meaningful?: establishing cut points for the Diabetes Distress Scale. Diabetes Care 2012;35:259-64.

2. Turner J, Kelly B. Emotional dimensions of chronic disease. West $J$ Med 2000;172:124-8.

3. Hamer M, Batty GD, Stamatakis E, et al. Hypertension awareness and psychological distress. Hypertension, 2010;56:547-50.

4. Li C, Ford ES, Zhao G, et al. Association between diagnosed diabetes and serious psychological distress among U.S. adults: the Behavioral Risk Factor Surveillance System, 2007. Int J Public Health 2009;54(Suppl 1):43-51.

5. Fisher L, Glasgow RE, Strycker LA. The relationship between diabetes distress and clinical depression with glycemic control among patients with type 2 diabetes. Diabetes Care 2010;33:1034-6.

6. Footman K, Roberts B, Tumanov S, et al. The comorbidity of hypertension and psychological distress: a study of nine countries in the former Soviet Union. J Public Health (Oxf) 2013;35:548-57.

7. Fisher L, Mullan JT, Arean P, et al. Diabetes distress but not clinical depression or depressive symptoms is associated with glycemic control in both cross-sectional and longitudinal analyses. Diabetes Care 2010;33:23-8.

8. Parving $\mathrm{HH}$. Controlling hypertension in diabetes. Acta Diabetol 2002;39:S35-40.

9. Sowers JR, Epstein M, Frohlich ED. Diabetes, hypertension, and cardiovascular disease an update. Hypertension 2001;37:1053-1059.

10. Polonsky WH, Fisher L, Earles J, et al. Assessing psychosocial distress in diabetes development of the diabetes distress scale. Diabetes care 2005;28:626-31.

11. Wagner HE, Austin BT, Davis C, et al. Improving chronic illness care: translating evidence into action. Health Aff (Millwood) 2001;20:64-78.

12. Eton DT, Ridgeway JL, Egginton JS, et al. Finalizing a measurement framework for the burden of treatment in complex patients with chronic conditions. Patient Relat Outcome Meas 2015;6:117-26.

13. National Institute of Public Health. National Health and Nutrition Survey. National results. Cuernavaca, Mexico: ENSANUT, 2012.

14. Fabian-SanMiguel MG, García-Sancho MS, Cobo-Abreu C. Prevalence of symptoms of anxiety and depression in patients with type 2 diabetes mellitus and its association with the type of treatment. Med Interna de México 2010;26:100-8.

15. López-Correa SM, Carranza-Madrigal J. Metabolic hypertension a reality in Mexico. Med Interna de México 2011;27:378-84.

16. Tovilla-Zárate $\mathrm{C}$, Juárez-Rojo I, Peralta-Jimenez $\mathrm{Y}$, et al. Prevalence of anxiety and depression among outpatients with type 2 diabetes in the Mexican population. PLOS ONE 2012;7:e36887.

17. Del Castillo ARJ, Reyes-Lagunes I, Guzmán M, et al. Adaptation of Emotional Distress Questionnaire associated with diabetes in Mexican population. In: Del Castillo A. (President), Adaptation of psychological instruments. Symposium held at the XXXI Congreso Interamericano de Psicología; México, DF, 2007.
18. Del Castillo Arreola A, Reyes Lagunes I. Validación convergente y divergente del cuestionario de áreas ProbleMa en diabetes (Paid) en Población Mexicana. In: Garcia Meraz M, del Castillo Arreola A Guzman Saldaña RME, et al., eds. Medición en psicología: del individuo a la interacción. Universidad Autónoma del Estado de Hidalgo, 2010:75-95.

19. Mexican Institute of Social Security. Report to the federal executive and the Congress of the Union on the financial situation and the risks of the Mexican Institute of Social Security 2012-2013. DF, Mexico: Mexican Institute of Social Security, 2013.

20. Holmes $\mathrm{TH}$, Rahe $\mathrm{RH}$. The social readjustment rating scale. J Psychosom Res 1967;11:213-18.

21. Nogueda-Orozco MJ, Pérez-Terán B, Barrientos-Casarrubias V, et al. Hospital Anxiety and Depression Scale (HADS): validation in Mexican patients with HIV infection. Psicología Iberoamericana 2013;21:29-7.

22. Doubova SV, Lamadrid-Figueroa H, Perez-Cuevas R. Use of electronic health records to evaluate the quality of care for hypertensive patients in Mexican family medicine clinics. $J$ Hypertens 2013;31:1714-23.

23. Pérez-Cuevas R, Doubova SV, Suarez-Ortega M, et al. Evaluating quality of care for patients with type 2 diabetes using electronic health record information in Mexico. BMC Med Inform Decis Mak 2012;12:50.

24. Worthington $\mathrm{R}$, Whittaker $\mathrm{T}$. Scale development research: a content analysis and recommendations for best practices. Couns Psychol 2006;34:806-38.

25. Veneziano L. A method for quantifying content validity of health-related questionnaires. Am J Health Behav 1997;21:67-70.

26. Carretero-Dios H, Pérez C. Standards for the development and the review of instrumental studies: considerations about test selection in psychological research. Int J Clin Health Psychol 2007;7:863-82.

27. Tabachnick BG, Fidell LS. Using multivariate statistics. Upper Saddle River, NJ: Pearson Education, 2001.

28. Hair JF, Anderson RE, Tatham RL, et al. Análisis Multivariante. Madrid: Prentice Hall Iberia, 1999.

29. Hirschfeld G, von Brachel R. Multiple-Group confirmatory factor analysis in R-A tutorial in measurement invariance with continuous and ordinal indicators. Pract Assess Res Eval 2014;19:2-12.

30. Taylor R. Interpretation of the correlation coefficient: a basic review. $J$ Diagn Med Sonogr 1990;6:35-9.

31. Fisher L, Mullan JT, Skaff MM, et al. Predicting diabetes distress in patients with Type 2 diabetes: a longitudinal study. Diabet Med 2009;26:622-7.

32. Fleiss JL. The design and analysis of clinical experiments. John Wiley \& Sons, 1986.

33. Borsa JC, Damásio BF, Bandeira DR. Cross-cultural adaptation and validation of psychological instruments: some considerations. Paidéia (Ribeirão Preto) 2012;22:423-32.

34. Joensen LE, Tapager I, Willaing I. Diabetes distress in Type 1 diabetes-a new measurement fit for purpose. Diabet Med 2013;30:1132-9.

35. Graue M, Haugstvedt A, Wentzel-Larsen T, et al. Diabetes-related emotional distress in adults: reliability and validity of the Norwegian versions of the Problem Areas in Diabetes Scale (PAID) and the Diabetes Distress Scale (DDS). Int J Nurs Stud 2012; 49:174-82.

36. Ting RZ, Nan H, Yu MW, et al. Diabetes-related distress and physical and psychological health in Chinese type 2 diabetic patients. Diabetes Care 2011;34:1094-6.

37. Ortiz MS, Baeza-Rivera MJ, Myers HF. Propiedades Psicométricas de la Escala de Estrés para Diabéticos En una Muestra de Pacientes Diabéticos Tipo II Chilenos. Terapia Psicológica 2013;31:281-6.

38. Coleman K, Austin BT, Brach C, et al. Evidence on the chronic care model in the new millennium. Health Aff (Millwood) 2009;28:75-85. 